\title{
Article \\ Can Exercise Help Regulate Blood Pressure and Improve Functional Capacity of Older Women with Hypertension against the Deleterious Effects of Physical Inactivity?
}

\author{
Luis Leitão ${ }^{1,2, *(\mathbb{D})}$, Moacir Marocolo ${ }^{3} \mathbb{D}$, Hiago L. R. de Souza ${ }^{3} \mathbb{D}$, Rhai André Arriel ${ }^{3} \mathbb{D}$, João Guilherme Vieira ${ }^{3} \mathbb{D}$, \\ Mauro Mazini ${ }^{4}$ (D) Hugo Louro ${ }^{5}$ and Ana Pereira ${ }^{1,2}$ \\ 1 Sciences and Technology Department, Superior School of Education of Polytechnic Institute of Setubal, \\ 2910-761 Setúbal, Portugal; ana.fatima.pereira@ese.ips.pt \\ 2 Life Quality Research Centre, 2040-413 Rio Maior, Portugal \\ 3 Post Graduate Program in Physical Education, Federal University of Juiz de For a, \\ Juiz de Fora 36036-900, Brazil; isamjf@gmail.com (M.M.); hlrsouza@gmail.com (H.L.R.d.S.); \\ rhaiarriel@bol.com.br (R.A.A.); joaoguilhermevds@gmail.com (J.G.V.) \\ 4 Graduate Program in Physical Education—Sudamerica Faculty, Cataguases 36774-552, Brazil; \\ personalmau@hotmail.com \\ 5 Sports Science School of Rio Maior, Polytechnic Institute of Santarém, 2040-413 Rio Maior, Portugal; \\ hlouro@esdrm.ipsantarem.pt \\ check for \\ updates \\ * Correspondence: luis.leitao@ese.ips.pt
}

Citation: Leitão, L.; Marocolo, M.; Souza, H.L.R.d.; Arriel, R.A.; Vieira, J.G.; Mazini, M.; Louro, H.; Pereira, A. Can Exercise Help Regulate Blood Pressure and Improve Functional Capacity of Older Women with Hypertension against the Deleterious Effects of Physical Inactivity? Int. J. Environ. Res. Public Health 2021, 18, 9117. https://doi.org/10.3390/ ijerph18179117

Academic Editors: Anna Polak,

Bogdan Bacik and

Agnieszka Nawrat-Szoltysik

Received: 30 June 2021

Accepted: 27 August 2021

Published: 29 August 2021

Publisher's Note: MDPI stays neutral with regard to jurisdictional claims in published maps and institutional affiliations.

Copyright: (c) 2021 by the authors. Licensee MDPI, Basel, Switzerland. This article is an open access article distributed under the terms and conditions of the Creative Commons Attribution (CC BY) license (https:// creativecommons.org/licenses/by/ $4.0 /)$.
Abstract: Background: Sedentarism and inactivity are risk factors for the development of hypertension. Thus, the prevention of the natural process of biological and physiological aging of older women through physical exercise results in higher benefits in preventing cardiovascular diseases and can be a key factor for its treatment. Multicomponent exercise (METP) is a training method that may help older women with hypertension by improving their quality of life and their response to treatment. Methods: Twenty-eight older Caucasian women with hypertension $(66.7 \pm 5.3$ years, $1.59 \pm 0.11 \mathrm{~m})$ performed a supervised METP program of nine months followed by three months of detraining (DT), and seventeen older women $(68.2 \pm 4.7$ years, $1.57 \pm 0.16 \mathrm{~cm})$ with hypertension maintained their daily routine, without exercise. Blood pressure (BP), resting heart rate, and functional capacity (FC) were evaluated at the beginning and at the end of the program, and after three months of DT. Results: The ME program improved $(p<0.05)$ systolic BP $(-5.37 \%)$, diastolic BP $(-5.67 \%)$, resting heart rate $(-7.8 \%)$, agility $(9.8 \%)$, lower body strength $(27.8 \%)$, upper body strength $(10.0 \%)$, and cardiorespiratory capacity $(8.6 \%)$. BP and FC deteriorated after the DT period $(p<0.05)$. Conclusion: Nine months of multicomponent exercise were sufficient to improve functional capacity and promote benefits in blood pressure, although was not sufficient to allow BP to reach the normal values of older women. The three month DT period without exercise caused the reversal of BP improvements but maintained the functional capacity of older women.

Keywords: older women; multicomponent exercise program; detraining; hypertension

\section{Introduction}

The average life expectancy and the number of older individuals have increased considerably during the past two decades, reinforcing the necessity to ensure the quality of life in older people [1,2]. Regular physical activity can reduce the effects of aging and a sedentary lifestyle, and prevent the development and progression of diseases and disabling conditions [3].

Among the most significant problems, cardiovascular diseases are the leading cause of death globally, and affect more women than men. The incidence of cardiovascular diseases is higher in older women due to menopause, which accentuates the negative changes in the metabolic profile and body composition [2,3]. Cardiovascular diseases are responsible 
for one-third of all deaths in women [4]. The main risk factors for the development of cardiovascular disease are high blood pressure and cholesterol, overweight and obesity, diabetes mellitus, and physical inactivity [1,2]. Hypertension is present in almost $70 \%$ of older adults and, despite therapeutic medication, these older adults have a high risk of cardiovascular events and mortality [5].

Therefore, it is crucial to create and apply interventions against these cardiovascular risks. Specifically, exercise, therapeutic medication, and healthy dietary behavior are the key factors to improve health and the quality of life of older women. Several studies have shown that physical activity, via aerobic exercise, resistance training, and/or METP, can have the same effect on lowering systolic blood pressure as antihypertensive therapy [5-7]. Exercise also has an acute effect in lowering the blood pressure of older adults for about $22 \mathrm{~h}$, known as postexercise hypotension (PEH), and can chronically increase functional capacity (FC). These actions have a clinical implication for preventing cardiovascular deleterious events $[5,7,8]$. METP is an exercise method that combines aerobic and resistance training, and is a low-cost intervention performed with own body weight, free weights, and elastic bands that can induce significant benefits in older women with or without hypertension $[1-3,7]$.

However, because this population group does not maintain adherence to regular physical exercise programs for long periods, both obtained metabolic and functional adaptations can decline after short detraining (DT) periods [9-11].

Therefore, the purpose of this longitudinal study was to investigate the effects of a multicomponent training and detraining period in older women with hypertension. Our hypothesis was that older women can significantly improve their hemodynamic health profile and functional capacity with multicomponent exercise over a period of 9 months of training, and maintain it following 3 months of detraining.

\section{Materials and Methods}

\subsection{Sample}

Forty-five Caucasian women aged between 60 and 70 years, functionally independent, volunteered to participate in this study. All participants underwent a medical evaluation when attending the experimental protocol program. The exclusion criteria were: (a) have already participated in any physical activity program; (b) osteoarticular dysfunction that may interfere with the execution of the proposed motion; (c) heart problems for which the exercise prescription is not recommended; and (d) medical contraindication. The inclusion criteria were: (a) have hypertension. The study was carried out according to the Helsinki Declaration and, prior to data collection, volunteers were informed about the procedures of the study and signed an informed consent. They were advised to maintain their previous lifestyle throughout the study, including dietary patterns and physical routines. Coffee, tea, alcohol and tobacco consumption, and strenuous exercise were prohibited $24 \mathrm{~h}$ before the experimental procedures.

\subsection{Procedures}

The participants were separated into two groups: experimental (EG: $N=28 ; 66.7 \pm 5.3$ years, $1.59 \pm 0.11 \mathrm{~m}$ ), engaged in a nine month multicomponent exercise training program followed by a three month detraining period; and the control group (CG: $N=17 ; 68.2 \pm 4.7$ years, $1.57 \pm 0.16 \mathrm{~m}$ ), which performed no exercise (Table 1 ). 
Table 1. Subject's anthropometric characteristics.

\begin{tabular}{ccccc}
\hline Variable & Group & $\begin{array}{c}\text { Baseline } \\
\mathbf{( B L )}\end{array}$ & $\begin{array}{c}\text { Post Exercise } \\
\text { (PE) }\end{array}$ & $\begin{array}{c}\text { Post Detraining } \\
\text { (PD) }\end{array}$ \\
\hline \multirow{2}{*}{ Body weight $(\mathrm{kg})$} & EG & $72.60 \pm 9.12$ & $71.49 \pm 9.19$ & $71.95 \pm 9.22$ \\
& CG & $71.58 \pm 10.29$ & $71.44 \pm 10.55$ & $71.97 \pm 10.50$ \\
$\mathrm{BMI}\left(\mathrm{kg} \cdot \mathrm{m}^{-2}\right)$ & EG & $30.67 \pm 3.18$ & $30.20 \pm 4.19$ & $30.39 \pm 5.50$ \\
& CG & $29,76 \pm 5.00$ & $29,70 \pm 5.13$ & $29.91 \pm 5.10$ \\
$\mathrm{BF}(\%)$ & EG & $39.12 \pm 2.42$ & $37.69 \pm 2.17$ & $38.29 \pm 2.14$ \\
& CG & $39.01 \pm 2.14$ & $38.95 \pm 2.04$ & $39.26 \pm 1.99$ \\
\hline
\end{tabular}

Data presented are mean \pm SD; body mass index (BMI); body fat percentage (BF).

Data were collected by the same examiner, under the same environmental conditions (10:00-12:00 h; $22-24{ }^{\circ} \mathrm{C} ; 55-65 \%$ humidity), prior of the multicomponent program, after nine months (at the end of the multicomponent exercise program and the beginning of the detraining period), and post three months of detraining. The same instruments were used at all times for measurements of anthropometric parameters (weight; height; body mass index), hemodynamic profile (blood pressure—systolic and diastolic pressure; resting heart rate), and functional capacity.

\subsubsection{Multicomponent Exercise Training Program (METP)}

METP consisted of 45 min sessions undertaken twice per week over nine consecutive months, for a total of 86 sessions. The program was conducted by a specialist in physical education training for older adults, according to the ACSM guidelines for exercise prescription [2]. Each training session consisted of aerobic and muscle resistance training, with appropriate music for the activity, age, and interests of the participants, and structured as follows:

(1) 5-8 min of global warm-up activity, including slow walking, calisthenics, and stretching exercises.

(2) 15-25 min of cardiorespiratory workout (aerobic choreography with moderate intensity), with intensity maintained at 2-3 of the adapted Borg Rating of Perceived Exertion scale (RPE) in the first month, and gradually increased to $4-5$ in the adapted Borg RPE.

(3) 15-20 min of resistance training with exercises performed in a circuit, involving exercises for the upper and lower body, agility, mobility, coordination, and social interaction, with a 20 to $30 \mathrm{~s}$ rest period between sets. Participants performed the weight resistance training using their own body weight (open and closed kinetic chain exercises) and elastic bands. Training intensity was progressive, particularly in the first month of training, to allow proper familiarization with the exercises and the correct and safe techniques of execution and breathing. The series and repetitions were increased each month, from 2 to 4 series and from 16 to 30 repetitions.

(4) 5-10 min of relaxation techniques and stretching for the upper and lower body. Static and dynamic stretching techniques were included in flexibility training.

\subsubsection{Detraining Period (DP)}

The DP took place over three consecutive months coinciding with the summer holidays. All volunteers were instructed to conduct their normal lifestyles, including dietary patterns and physical routines, and avoid any type of systematic exercise. Participants were systematically contacted to ensure that they were fulfilling the DP requirements. The testing assessment procedures of DT were performed under the same conditions as for the METP.

\subsubsection{Hemodynamic Profile}

The measurements of blood pressure, systolic blood pressure (SBP), and diastolic blood pressure (DBP) were conducted using a digital sphygmomanometer (Omron Digital Blood Pressure Monitor HEM-907, Matsusaka, Japan). Resting heart rate ( $\left.\mathrm{HR}_{\text {rest }}\right)$ was also measured. These measurements were taken three times under the same conditions in a 
seated resting position and with the left arm in support, after at least 5 min (AHA, 2005). A scale (OMRON BF 303, Matsusaka, Japan), a stadiometer (Seca, Hamburg, Germany), and bioelectrical impedance analysis were used for body mass $(\mathrm{kg})$, height $(\mathrm{cm})$, and body mass index $\left(\mathrm{BMI}, \mathrm{kg} \cdot \mathrm{m}^{-2}\right)$ and body fat percentage $(\mathrm{BF}, \%)$, respectively.

\subsubsection{Functional Capacity Battery Test}

The Functional Capacity Battery Test consisted of the Senior Fitness Test [12]. This protocol comprises six motor tests: upper limbs strength (arm curl); lower limbs strength (30 s chair stand); upper limbs flexibility (back scratch); lower limbs flexibility (chair sit-and-reach); agility/dynamic balance ( 8 foot up-and-go); and aerobic capacity (6 min walk).

\subsection{Statistical Analysis}

We used SPSS 19.0 for Windows (SPSS Inc., Chicago, IL, USA) for data analysis. Descriptive procedures of central tendency and dispersion were used to characterize the variable values and the normality of our sample was verified by the Shapiro-Wilk test. For inferential analysis of data, we used repeated measures ANOVA to compare, within and between groups, the mean values of each variable over the time, followed by the post-hoc Bonferroni test. The sphericity assumption was verified through the Mauchly test. The meaningfulness of the outcomes was estimated through the effect size (ES, Cohen's d, mean divided by the standard deviation): 0.2 or less is a small ES, about 0.5 is a moderate ES, and 0.8 or more is a large ES. The delta percentage $(\Delta \%)$ was calculated via the standard formula: $\Delta \%=[($ posttest score - pretest score $) /$ pretest score $] \times 100$. For all statistical procedures, the statistical significance accepted was $p \leq 0.05$.

\section{Results}

The participants of EG completed the exercise program with an attendance of $88 \%$. After METP, all values of the health profiles were significantly better $(p<0.05)$ than those observed at the beginning of the study (Table 2) but not after three months of detraining (Tables 2 and 3).

Table 2. Delta percentage differences of parameters after MEP and detraining period.

\begin{tabular}{ccccccccccc}
\hline & Group & $\begin{array}{c}\text { SBP } \\
\mathbf{( \% )}\end{array}$ & $\begin{array}{c}\text { DBP } \\
\mathbf{( \% )}\end{array}$ & $\begin{array}{c}\mathbf{H R}_{\text {rest }} \\
\mathbf{( \% )}\end{array}$ & $\begin{array}{c}\text { UBS } \\
\mathbf{( \% )}\end{array}$ & $\begin{array}{c}\text { LBS } \\
\mathbf{( \% )}\end{array}$ & $\begin{array}{c}\text { UBF } \\
\mathbf{( \% )}\end{array}$ & $\begin{array}{c}\text { LBF } \\
\mathbf{( \% )}\end{array}$ & $\begin{array}{c}2 \text { 2TUG } \\
(\mathbf{\%})\end{array}$ & $\begin{array}{c}\text { 6MWT } \\
\mathbf{( \% )}\end{array}$ \\
\hline \multirow{2}{*}{ BL vs. PE } & EG & $-5.4^{*}$ & $-5.6^{*}$ & $-7.7^{*}$ & $10^{*}$ & $27.8^{*}$ & $53.9^{*}$ & $100^{*}$ & $-9.8^{*}$ & $8.6^{*}$ \\
& CG & -0.4 & -0.1 & 0.3 & 1.1 & -5.9 & 7 & 17.1 & -0.7 & -0.7 \\
\multirow{2}{*}{ PE vs. PD } & EG & $1.1^{*}$ & $0.1^{*}$ & $7^{*}$ & $-4.5^{*}$ & $-13^{*}$ & $-33.3^{*}$ & $-37.5^{*}$ & $3.5^{*}$ & $-4.8^{*}$ \\
& CG & 0.4 & 0.2 & 0.6 & 0.4 & 1.1 & -6.4 & -14.2 & -0.5 & -0.3 \\
\hline
\end{tabular}

Data presented are the delta percentages $(\Delta \%)$ : (a) before the nine month multicomponent exercise program $(\mathrm{BL})$ and post exercise/beginning of detraining (PE); (b) post exercise and post detraining (PD) of systolic blood pressure (SBP), diastolic blood pressure (DBP), resting heart rate $\left(\mathrm{HR}_{\text {rest }}\right)$, upper body strength (UBS), lower body strength (LBS), upper body flexibility (UBF), lower body flexibility (LBF), agility/dynamic balance (2TUG), aerobic endurance six-minute walk test $(6 \mathrm{MWT}) ;{ }^{*} p<0.05$.

After the multicomponent exercise program, body mass index (BMI), percentage $(\mathrm{BF} \%)$, resting heart rate $\left(\mathrm{HR}_{\mathrm{rest}}\right)$, and systolic $(\mathrm{SBP})$ and diastolic blood pressure (DBP) improved significantly $(p<0.005)$ and declined significantly after detraining $(p<0.05)$, losing all of the benefits acquired over nine months of ME. The functional capacity (FC) improved with the program and decreased significantly after three months of detraining, but improved compared with the baseline values. The CG group maintained the baseline values throughout the study. 
Table 3. Effects of the multicomponent exercise program and detraining in the hemodynamic health profile and functional capacity of older women with hypertension.

\begin{tabular}{|c|c|c|c|c|c|c|c|c|c|c|c|c|c|c|}
\hline & \multicolumn{7}{|c|}{ CG } & \multicolumn{7}{|c|}{ EG } \\
\hline & \multirow{3}{*}{ BL } & \multirow{3}{*}{ PE } & \multirow{3}{*}{ PD } & \multicolumn{4}{|c|}{ BL vs. PD } & \multirow{3}{*}{ BL } & \multirow{3}{*}{ PE } & \multirow{3}{*}{ PD } & \multicolumn{4}{|c|}{ BL vs. PD } \\
\hline & & & & \multicolumn{2}{|c|}{ Confidence Interval } & \multirow[t]{2}{*}{ ES } & \multirow[t]{2}{*}{$p$} & & & & \multicolumn{2}{|c|}{ Confidence Interval } & \multirow[t]{2}{*}{ ES } & \multirow[t]{2}{*}{$p$} \\
\hline & & & & Lower & Upper & & & & & & Lower & Upper & & \\
\hline $\mathrm{SBP}(\mathrm{mmHg})$ & $144.47 \pm 3.41$ & $143.94 \pm 2.36$ & $144.12 \pm 2.24$ & -1.59 & 2.54 & 0.12 & 0.64 & $148.96 \pm 7.18$ & $141.36 \pm 3.49^{*}$ & $151.86 \pm 9.27^{+}$ & -4.97 & -0.82 & 0.35 & 0.01 \\
\hline DBP (mmHg) & $86.47 \pm 2.47$ & $86.32 \pm 2.78$ & $86.65 \pm 2.32$ & -0.91 & 0.56 & 0.08 & 0.62 & $88.36 \pm 5.03$ & $82.96 \pm 5.00 *$ & $84.50 \pm 9.81^{+}$ & 0.8 & 6.91 & 0.50 & 0.02 \\
\hline $\mathrm{HR}_{\text {rest }}(\mathrm{bpm})$ & $81.47 \pm 3.95$ & $81.52 \pm 4.7$ & $81.11 \pm 4.06$ & -0.05 & 0.76 & 0.09 & 0.08 & $77.32 \pm 7.38$ & $70.96 \pm 8.81 *$ & $75.61 \pm 7.81^{+}$ & 0.54 & 2.89 & 0.23 & 0.01 \\
\hline LBS (repetitions) & $17.24 \pm 2.73$ & $16.35 \pm 3.05$ & $17.06 \pm 2.35$ & -0.46 & 0.81 & 0.07 & 0.57 & $18.11 \pm 2.36$ & $22.79 \pm 3.01 *$ & $20.39 \pm 2.61^{+}$ & -2.46 & -2.11 & 0.91 & 0.00 \\
\hline UBS (repetitions) & $19.36 \pm 1.27$ & $20.35 \pm 1.22$ & $20.12 \pm 2.32$ & -2.19 & 0.66 & 0.41 & 0.27 & $19.54 \pm 1.88$ & $21,54 \pm 2.69 *$ & $20.71 \pm 2.11^{+}$ & -1.97 & -0.39 & 0.59 & 0.01 \\
\hline 2TUG (s) & $5.75 \pm 0.20$ & $5.71 \pm 0.24$ & $5.68 \pm 0.21$ & -0.06 & 0.19 & 0.34 & 0.28 & $5.70 \pm 0.42$ & $5.21 \pm 0.53 *$ & $5.40 \pm 0.56^{+}$ & 0.12 & 0.48 & 0.61 & 0.00 \\
\hline LBF $(\mathrm{cm})$ & $1.76 \pm 2.61$ & $2.06 \pm 2.72$ & $2.01 \pm 2.55$ & -0.75 & 0.63 & 0.10 & 0.86 & $1.54 \pm 2.17$ & $3.64 \pm 1.83 *$ & $2.46 \pm 1.75^{+}$ & -2.33 & -0.31 & 0.47 & 0.01 \\
\hline $\mathrm{UBF}(\mathrm{cm})$ & $-5.88 \pm 3.71$ & $-5.47 \pm 3.29$ & $-5.82 \pm 3.53$ & -1.17 & 0.70 & 0.02 & 0.60 & $-4.96 \pm 4.28$ & $-2.46 \pm 4.74^{*}$ & $-3.64 \pm 3.88^{+}$ & -1.52 & -0.33 & 0.32 & 0.00 \\
\hline 6MWT (m) & $576.64 \pm 52.89$ & $572.35 \pm 41.31$ & $570.59 \pm 47.07$ & -9.33 & 13.45 & 0.12 & 0.71 & $563.93 \pm 56.69$ & $623.93 \pm 60.31$ * & $586.96 \pm 59.99^{+}$ & -30.26 & -15.81 & 0.39 & 0.00 \\
\hline
\end{tabular}

Data presented are mean $\pm \mathrm{SD}$; before multicomponent training $(\mathrm{BL})$, post exercise $(\mathrm{PE})$, and post detraining $(\mathrm{PD})$ of systolic blood pressure (SBP), diastolic blood pressure (DBP), resting heart rate $\left(\mathrm{HR}_{\text {rest }}\right)$, upper body strength (UBS), lower body strength (LBS), upper body flexibility (UBF), lower body flexibility (LBF), agility/dynamic balance (2TUG), aerobic endurance six-minute walk test $(6 \mathrm{MWT}) .{ }^{*} p<0.05$, significant improvements after training period of multicomponent training program; ${ }^{+} p<0.05$, significant decreases with detraining period after multicomponent training program.

\section{Discussion}

The aim of this study was to analyze the changes in the hemodynamic health profile and functional capacity produced during nine month multicomponent training and three months detraining periods in older Caucasian women with hypertension. The major finding indicated that a systematic supervised multicomponent exercise program with nine months of training in older women with hypertension resulted in better blood pressure regulation, to near to normal values, and improved FC. However, three months of detraining were sufficient to return blood pressure to baseline values.

Our hemodynamic and FC improvements can be explained by the combined types of exercise of METP, which promote the specific benefits of aerobic exercise and resistance training. In the hemodynamic profile, the improvements found in $\mathrm{HR}_{\text {rest }}$ and blood pressure (systolic pressure: $-5.37 \%$; diastolic pressure: $-5.62 \%$ ) as a result of the training period are in agreement with other studies $[8,13,14]$ that found that exercise helps to lower blood pressure. According to the meta-analysis of Kelley and Kelley [15], resistance training decreases SBP and DBP by $2 \%$ and $4 \%$, respectively. Cornelissen et al. [7] verified decreases of 3.2 and $3.5 \mathrm{mmHg}$ in $\mathrm{SBP}$ and $\mathrm{DBP}$, respectively, and a reduction in resting heart rate due to cardiorespiratory improvements. Each meta-analysis shows that exercise can decrease SBP and DBP in normotensive and hypertensive older adults. Although the mechanisms underlying the lowering effect of exercise on SBP are not fully understood, neuro-hormonal $[16,17]$, structural, and functional vascular adaptations were recently proposed as possible mechanisms [17]. As functional adaptations, it was suggested that aerobic training may possibly reduce sympathetic nervous activity and subsequent release of norepinephrine, lower endothelin-1 levels [18], and increase nitric oxide production [19], thereby reducing vasoconstriction and peripheral vascular resistance. According to Sosner et al. [8], aerobic exercise can reduce systolic blood pressure by $5.09 \mathrm{mmHg}$, regardless of intensity, duration and frequency of exercise, and this benefit is more substantial if a weight loss is present. Cornilissen et al. [13] reported that exercise can reduce systolic pressure by $6.9 \mathrm{mmHg}$. This reduction is higher in hypertensive individuals than in normotensive individuals [20], and can be higher in individuals having higher high blood pressure values. Furthermore, taking antihypertensive medication does not promote changes in blood pressure during the day [8]. Leitão et al. [10] reported a reduction of $3.80 \%$ in systolic pressure and $5.48 \%$ in diastolic pressure after nine months of MEP. Delgado-Floody et al. [21] reported a reduction of $7.1 \mathrm{mmHg}$ in systolic pressure and $5.43 \mathrm{mmHg}$ in diastolic pressure after a 16 week HIIT intervention, booth in normotensive individuals. In hypertensive subjects, Delgado-Floody et al. [21] reported a reduction of $8.70 \mathrm{mmHg}$ in systolic pressure and $4.9 \mathrm{mmHg}$ in diastolic pressure, similar to the results of our study. Cornelissen and Smart [7] only reported a decrease of $2.2 \mathrm{mmHg}$ in systolic 
pressure with concurrent training. A $3 \mathrm{mmHg}$ reduction can promote the reduction in stroke mortality and coronary heart disease by $8 \%$ and $5 \%$, respectively [8], and can be maximized if exercise is applied as a long-term practice [3]. The blood pressure in our study did not reach normative values with nine months of METP, which may indicate that older women with hypertension may need a longer period of exercise to achieve these values. The FC improvements observed were similar to those of Hortobágyi et al. [22] and Marcos-Pardo et al. [23]. After 8 months of METP, Blasco-Lafarga et al. [24] reported improvements in lower body strength $(20.23 \%)$, agility $(22.32 \%)$, and aerobic capacity $(14.54 \%)$, and Leitão et al. [10] observed a $11.06 \%$ improvement in aerobic capacity after 9 months of MEP, both in normotensive older women.

After detraining, blood pressure returned to near to baseline values in hypertensive older women. This result was not previously found in other studies as a result of the decline reported after detraining. Elliot et al. [25] reported a 9.32\% increase in systolic pressure and a $1.52 \%$ increase in diastolic pressure after the suspension of a resistance training program, and Leitão et al. [10] reported a $4.13 \%$ increase in systolic pressure and a 3.38\% increase in diastolic pressure after nine months of MEP. Both studies involved normotensive older women, and these results may indicate that normotensive older adults respond in a different way to detraining than hypertensive older women. In our study, FC declined with detraining but maintained a portion of the improvements observed with the MEP, results that were similar to those of other studies [9,10,26,27]. Martinez-Aldao et al. [28] reported $-5.6 \%$ lower body strength, $-4.6 \%$ agility, and $-1.3 \%$ aerobic capacity after 8 months of MEP. Esain et al. [29], after 9 months of MEP, reported a decline of $5.8 \%$ in agility and 3.1\% in upper body strength. These modifications can have important health consequences for older adults via an increased in the risk of cardiovascular disease $[9,10,26,29-31]$. These results suggest that exercise focused on MEP can produce a strong positive effect by protecting older women with hypertension against health declines associated with age, and that detraining periods should be avoided [10].

\section{Conclusions}

The hemodynamic health profile and functional capacity of older women with hypertension can be improved, to those of normotensive older women, through nine months of a multicomponent exercise program. However, such a program was not sufficient to achieve normal BP values, and a three month detraining period was sufficient to eliminate the blood pressure benefits in hypertensive older women. METP is a low-cost and effective exercise method that can be applied in the community. Interruptions should be avoided when prescribing exercise to older adults to maintain or reduce the negative impact of detraining and their risk of heart disease, and to maintain or increase their daily activities, health, and quality of life.

Author Contributions: Conceptualization, L.L., J.G.V. and A.P.; data curation, M.M. (Moacir Marocolo), M.M. (Mauro Mazini) and H.L.; formal analysis, M.M. (Moacir Marocolo), L.L. and A.P.; investigation, L.L., M.M. (Moacir Marocolo) and A.P.; Methodology, L.L., R.A.A., H.L.R.d.S. and A.P. project administration, L.L. and A.P.; resources, L.L., J.G.V. and H.L.; supervision, H.L. and L.L.; validation, H.L.R.d.S., R.A.A. and M.M. (Moacir Marocolo); visualization, M.M. (Moacir Marocolo) and H.L.; writing—original draft, L.L., M.M. (Moacir Marocolo) and A.P.; writing—review and editing, L.L., M.M. (Moacir Marocolo) and H.L. All authors have read and agreed to the published version of the manuscript.

Funding: This research was funded by the Portuguese Foundation for Science and Technology, I.P., Grant/Award Number UIDP/04748/2020.

Institutional Review Board Statement: The study was conducted according to the guidelines of the Declaration of Helsinki, and approved by the Local Ethics Committee (3749878/2019).

Informed Consent Statement: Informed consent was obtained from all subjects involved in the study.

Data Availability Statement: The data presented in this study are available on request from the corresponding author. 
Conflicts of Interest: The authors declare no conflict of interest.

\section{References}

1. Fragala, M.S.; Cadore, E.L.; Dorgo, S.; Izquierdo, M.; Kraemer, W.J.; Peterson, M.D.; Ryan, E.D. Resistance training for older adults: Position statement from the National Strength and Conditioning Association. J. Strength Cond. Res. 2019, 33, $2019-2052$. [CrossRef] [PubMed]

2. Chodzko-Zajko, W.J.; Proctor, D.N.; Fiatarone Singh, M.A.; Minson, C.T.; Nigg, C.R.; Salem, G.J.; Skinner, J.S. American College of Sports Medicine position stand. Exercise and physical activity for older adults. Med. Sci. Sports Exerc. 2009, 41, 1510-1530. [CrossRef] [PubMed]

3. Pescatello, L.S.; MacDonald, H.V.; Lamberti, L.; Johnson, B.T. Exercise for hypertension: A prescription update integrating existing recommendations with emerging research. Curr. Hypertens. Rep. 2015, 17, 87. [CrossRef] [PubMed]

4. Benjamin, E.J.; Virani, S.S.; Callaway, C.W.; Chamberlain, A.M.; Chang, A.R.; Cheng, S.; Chiuve, S.E.; Cushman, M.; Delling, F.N.; Deo, R. American Heart Association Council on Epidemiology and Prevention Statistics Committee and Stroke Statistics Subcommittee. Heart Disease and Stroke Statistics-2018 Update: A Report from the American Heart Association. Circulation 2018, 137, e67-e492, Erratum in Circulation 2018, 137, e493. [CrossRef]

5. Costa, I.B.B.; Schwade, D.; Macêdo, G.A.D.; Browne, R.A.V.; Farias-Junior, L.F.; Freire, Y.A.; Costa, E.C. Acute antihypertensive effect of self-selected exercise intensity in older women with hypertension: A crossover trial. Clin. Interv. Aging 2019, 14, 1407-1418. [CrossRef]

6. Naci, H.; Salcher-Konrad, M.; Dias, S.; Blum, M.R.; Sahoo, S.A.; Nunan, D.; Ioannidis, J.P.A. How does exercise treatment compare with antihypertensive medications? A network meta-analysis of 391 randomised controlled trials assessing exercise and medication effects on systolic blood pressure. Br. J. Sports Med. 2018, 53, 859-869. [CrossRef]

7. Cornelissen, V.A.; Smart, N.A. Exercise training for blood pressure: A systematic review and meta-analysis. J. Am. Heart Assoc. 2013, 2, e004473. [CrossRef]

8. Sosner, P.; Guiraud, T.; Gremeaux, V.; Arvisais, D.; Herpin, D.; Bosquet, L. The ambulatory hypotensive effect of aerobic training: A reappraisal through a meta-analysis of selected moderators. Scand. J. Med. Sci. Sports 2016, 27, 327-341. [CrossRef] [PubMed]

9. Leitão, L.F.; Brito, J.; Leitão, A.; Pereira, A.; Conceição, A.; Silva, A.; Louro, H.J.M. Retenção da capacidade funcional em mulheres idosas após a cessação de um programa de treino multicomponente: Estudo longitudinal de 3 anos. Motricidade 2015, 11, 81-91. [CrossRef]

10. Leitão, L.; Pereira, A.; Mazini, M.; Venturini, G.; Campos, Y.; Vieira, J.; Novaes, J.; Vianna, J.; Silva, S.; Louro, H. Effects of Three Months of Detraining on the Health Profile of Older Women after a Multicomponent Exercise Program. Int. J. Environ. Res. Public Health 2019, 16, 3881. [CrossRef]

11. Pickering, T.G.; Hall, J.E.; Appel, L.J.; Falkner, B.E.; Graves, J.; Hill, M.N.; Jones, D.W.; Kurtz, T.; Sheps, S.G.; Roccella, E.J. Recommendations for blood pressure measurement in humans and experimental animals: Part 1: Blood pressure measurement in humans: A statement for professionals from the Subcommittee of Professional and Public Education of the American Heart Association Council on High Blood Pressure Research. Circulation 2005, 111, 697-716. [PubMed]

12. Rikli, R.E.; Jones, C.J. Development and validation of a functional fitness test for community residing older adults. J. Aging Phys. 1999, 7, 129-161. [CrossRef]

13. Cornelissen, V.A.; Buys, R.; Smart, N.A. Endurance exercise beneficially affects ambulatory blood pressure: A systematic review and meta-analysis. J. Hypertens. 2013, 31, 639-648. [CrossRef] [PubMed]

14. Molmen-Hansen, H.E.; Stolen, T.; Tjonna, A.E.; Aamot, I.L.; Ekeberg, I.S.; Tyldum, G.A.; Stoylen, A. Aerobic interval training reduces blood pressure and improves myocardial function in hypertensive patients. Eur. J. Prev. Cardiol. 2011, 19, 151-160. [CrossRef] [PubMed]

15. Kelley, G.A.; Kelley, K.S. Progressive resistance exercise and resting blood pressure: A meta-analysis of randomized controlled trials. Hypertension 2000, 35, 838-843. [CrossRef] [PubMed]

16. Ben-Sira, D.; Oliveira, J. Hypertension in aging: Pysical activity as primary prevention. Eur. Rev. Aging Phys. Act. 2007, 4, 85-89. [CrossRef]

17. Pescatello, L.S.; Franklin, B.A.; Fagard, R.; Farquhar, W.B.; Kelley, G.A.; Ray, C.A. American College of Sports Medicine Position Stand: Exercise and hypertension. Med. Sci. Sports Exerc. 2004, 36, 533-553. [CrossRef]

18. Maeda, S.; Tanabe, T.; Miyauchi, T.; Otsuki, T.; Sugawara, J.; Lemitsu, M. Aerobic exercise training reduces plasma endothelin-1 concentration in older women. J. Appl. Physiol. 2003, 95, 336-341. [CrossRef]

19. Rosamond, W.; Flegal, K.; Friday, G.; Furie, K.; Go, A.; Greenlund, K. American Heart Association Statistics Committee and Stroke Statistics Subcommittee. Heart disease and stroke statistics-2007 update: A report from the American Heart Association Statistics Committee and Stroke Statistics Subcommittee. Circulation 2007, 115, e69-e171. [CrossRef]

20. Mancia, G.; Fagard, R.; Narkiewicz, K.; Redon, J.; Zanchetti, A.; Bohm, M.; Christiaens, T.; Cifkova, R.; De Backer, G.; Dominiczak, A.; et al. ESH/ESC guidelines for the management of arterial hypertension: The Task Force for the Management of Arterial Hypertension of the European Society of Hypertension (ESH) and of the European Society of Cardiology (ESC). Eur. Heart J. 2013, 34, 2159-2219. [PubMed]

21. Delgado-Floody, P.; Izquierdo, M.; Ramírez-Vélez, R.; Caamaño-Navarrete, F.; Moris, R.; Jerez-Mayorga, D.; Álvarez, C. Effect of High-Intensity Interval Training on Body Composition, Cardiorespiratory Fitness, Blood Pressure, and Substrate Utilization 
During Exercise Among Prehypertensive and Hypertensive Patients with Excessive Adiposity. Front. Physiol. 2020, $11,558910$. [CrossRef] [PubMed]

22. Hortobágyi, T.; Deák, D.; Farkas, D.; Blényesi, E.; Török, K.; Granacher, U.; Tollár, J. Effects of Exercise Dose and Detraining Duration on Mobility at Late Midlife: A Randomized Clinical Trial. Gerontology 2021. [CrossRef] [PubMed]

23. Marcos-Pardo, P.J.; González-Gálvez, N.; Gea-García, G.M.; López-Vivancos, A.; Espeso-García, A.; Gomes de Souza Vale, R. Sarcopenia as a Mediator of the Effect of a Gerontogymnastics Program on Cardiorespiratory Fitness of Overweight and Obese Older Women: A Randomized Controlled Trial. Int. J. Environ. Res. Public Health 2020, 17, 7064. [CrossRef]

24. Blasco-Lafarga, C.; Cordellat, A.; Forte, A.; Roldán, A.; Monteagudo, P. Short and Long-Term Trainability in Older Adults: Training and Detraining Following Two Years of Multicomponent Cognitive-Physical Exercise Training. Int. J. Environ. Res. Public Health 2020, 17, 5984. [CrossRef]

25. Elliott, K.; Sale, C.; Cable, N. Effects of resistance training and detraining on muscle strength and blood lipid profiles in postmenopausal women. Br. J. Sports Med. 2002, 36, 340-344. [CrossRef] [PubMed]

26. Sakugawa, R.L.; Moura, B.M.; Orssatto, L.; Bezerra, E.S.; Cadore, E.L.; Diefenthaeler, F. Effects of resistance training, detraining, and retraining on strength and functional capacity in elderly. Aging Clin. Exp. Res. 2019, 31, 31-39. [CrossRef]

27. Pereira, A.; Izquierdo, M.; Silva, A.J.; Costa, A.M.; González-Badillo, J.J.; Marques, M.C. Muscle performance and functional capacity retention in older women after high-speed power training cessation. Exp. Gerontol. 2012, 47, 620-624. [CrossRef]

28. Martínez-Aldao, D.; Diz, J.C.; Varela, S.; Sánchez-Lastra, M.A.; Ayán, C. Impact of a five-month detraining period on the functional fitness and physical activity levels on active older people. Arch. Gerontol. Geriatr. 2020, 91, 104191. [CrossRef]

29. Esain, I.; Gil, S.M.; Bidaurrazaga-Letona, I.; Rodriguez-Larrad, A. Effects of 3 months of detraining on functional fitness and quality of life in older adults who regularly exercise. Aging Clin. Exp. Res. 2019, 31, 503-510. [CrossRef]

30. Nolan, P.; Keeling, S.; Robitaille, C.; Buchanan, C.; Dalleck, L. The effect of detraining after a period of training on cardiometabolic health in previously sedentary individuals. Int. J. Environ. Res. Public Health 2018, 15, 2303. [CrossRef] [PubMed]

31. Carvalho, J.; Marques, E.; Ascensão, A.; Magalhães, J.; Marques, F.; Mota, J. Multicomponent exercise program improves blood lipid profile and antioxidant capacity in older women. Arch. Gerontol. Geriatr. 2010, 51, 1-5. [CrossRef] [PubMed] 